\title{
Analisis Model Supply Pada Jaringan Sistem Kelistrikan di Fakultas Teknik Universitas Udayana Bukit Jimbaran
}

\author{
Margareta Yuniari $^{1}$, I. A. D. Giriantari ${ }^{2}$, I. W. Sukerayasa ${ }^{3}$
}

\begin{abstract}
The addition of the power source to the main network is one way to improve the quality of electric power system, network reliability and to reduce power losses. The addition of the energy source is a smart microgrid system. The smart microgrid technology is a technology that uses renewable energy as a main supply. Smart microgrid system consists of a $24 \mathrm{kWp}$ solar power, Wind Turbine $5 \mathrm{kWp}$ system $240 \mathrm{kVAh}$ battery and genset $20 \mathrm{kVA}$. The smart microgrid system to be implemented at the Engineering Faculty of Udayana University. The results showed the power loss (losses) on the electrical grid at FT Bukit Jimbaran before the advent of smart microgrid system to the network, acquired losses of $6.4 \mathrm{~kW}$ or $3.68 \%$ of the total load when the network is supplied from PLN and after the inclusion of smart microgrid system and generator sets to the grid obtained by losses of $1.2 \mathrm{~kW}$ or decreased losses of $0.69 \%$ of the total expenses of $173.54163 \mathrm{~kW}$. Reliability indices obtained at the Technical University of Udayana network after the entry smart microgrid system when interconnected with PLN namely SAIFI: 0.1029, SAIDI: 1.9229 hours / customer, and CAIDI: 18.686 hours / interruption.
\end{abstract}

Intisari -Penambahan sumber energi listrik ke jaringan utama merupakan salah satu cara untuk meningkatkan kualitas sistem tenaga listrik, keandalan jaringan dan menurunkan rugirugi daya. Teknologi smart microgrid merupakan teknoilogi yang memanfaatkan sumber energy terbarukan sebagai sumber suplai. Smart microgrid system terdiri dari PLTS $24 \mathrm{kWp}$, Wind Turbin $5 \mathrm{kWp}$ dengan sistem baterai $240 \mathrm{kVAh}$ dan genset 20 kVA ini diimplemetasikan di Fakultas Teknik Universitas Udayana. Hasil penelitian menunjukkan hasil rugi-rugi daya (losses) pada jaringan listrik FT Bukit Jimbaran sebelum masuknya smart microgrid system ke jaringan, diperoleh losses sebesar $6,4 \mathrm{~kW}$ atau $3,68 \%$ dari total beban ketika jaringan disuplai dari PLN dan setelah masuknya smart microgrid system dan genset ke jaringan PLN diperoleh losses sebesar 1,2 kW atau mengalami penurunan losses sebesar 0,69 \% dari total beban sebesar $173,54163 \mathrm{~kW}$. Indeks keandalan yang diperoleh pada jaringan Fakultas Teknik Universitas Udayana setelah masuknya smart microgrid system ketika terinterkoneksi dengan PLN yakni SAIFI: 0,1029, SAIDI:1.9229 jam/pelanggan, dan CAIDI:18,686 jam/gangguan

Kata Kunci - Smart microgrid system, PLTS, Wind Turbin, generator set, losses, keandalan

${ }^{1}$ Mahasiswa, Jurusan Teknik Elektro dan Komputer Fakultas Teknik Universitas Udayana, Jln. Kampus Bukit Jimbaran 80361 INDONESIA (telp: 0361-703315; fax: 0361-4321;e-mail: margaretayuniari@gmail.com

${ }^{2,3}$ Dosen ,Jurusan Teknik Elektro dan Komputer Fakultas Teknik Universitas Udayana, Jln. Jalan Kampus Bukit Jimbaran 80361 INDONESIA (telp: 0361-703315; fax: 0361-4321; e-mail: 'dayu.giriantari@unud..ac.id, ${ }^{2}$ sukerayasa@unud.ac.id

\section{PENDAHULUAN}

Fakultas Teknik Universitas Udayana terdiri dari 5 jurusan, yakni Jurusan Teknik Sipil, Teknik Elektro, Teknik Mesin, Arsitektur, dan Teknologi Informatika. Kelima jurusan ini memiliki gedung-gedung yang digunakan untuk perkuliahan, laboratorium, dan gedung dekanat. Secara umum, kebutuhan energi listrik di kampus Universitas Udayana disuplai oleh trafo KA - 0298 dengan kapasitas terpasang adalah 200 kVA.

Di Jurusan Teknik Elektro Universitas Udayana saat ini sedang dipasang Smart microgrid system. Smart microgrid system yang terdiri dari PLTS dengan kapasitas $24 \mathrm{kWp}$, Wind Turbin $5 \mathrm{kWp}$ yang menggunakan sistem baterai $240 \mathrm{kVAh}$ sebagai media penyimpan energi dan generator set $20 \mathrm{kVA}$ Smart microgrid system akan dipasang gedung DH Jurusan Teknik Elektro dan Komputer (JTEK). Smart microgrid system ini akan menyuplai beban yang ada di gedung DH JTEK yang digunakan sebagai gedung perkuliahan. Tidak hanya gedung DH yang akan disupai dari smart microgrid system, akan tetapi gedung DI dan DJ akan mendapat suplai dari sistem untuk sistem penerangan selama hari libur. Gedung-gedung lain ada di Fakultas Teknik, selain Jurusan Teknik Sipil, akan mendapat suplai dari smart microgrid system yang akan diinterkoneksikan dengan genset $60 \mathrm{kVA}$ dan jaringan PLN.

Pada penelitian ini analisis kondisi sistem kelistrikan di Fakultas Teknik Bukit Jimbaran dibagi menjadi dua bagian, yakni analisis kondisi kelistrikan sebelum masuknya smart microgrid system dan analisis sesudah masuknya smart microgrid system. Kedua kondisi ini akan dianalisis rugi-rugi daya dan keandalan jaringan. menggunakan Load Flow Analisys dan Reliabillity Accessment.

\section{SISTEM MICROGRID}

Microgrid adalah sumber energi dengan beban saling terhubung yang pada akhirnya membentuk suatu jaringan yang dapat dikontrol dalam satu entitas [1]. Sebuah microgrid dapat beroperasi ketika terhubung dengan jaringan (on grid) maupun beroperasi secara mandiri (off grid). Microgrid merupakan salah satu sistem dengan sejumlah beban yang terhubung dan didistribusikan secara parallel atau secara umum dikenal dengan sebagai sistem pulau [5]. Pembangkit listrik pada sistem microgrid merupakan gabungan atau kumpulan dari pembangkit listik konvensional dan sumber energy terbarukan seperti surya, angin, biomassa, mikrohidro,dan sebagainya [3][6][9]. Sistem microgrid secara umum dapat ditunjukkan pada gambar 1. 


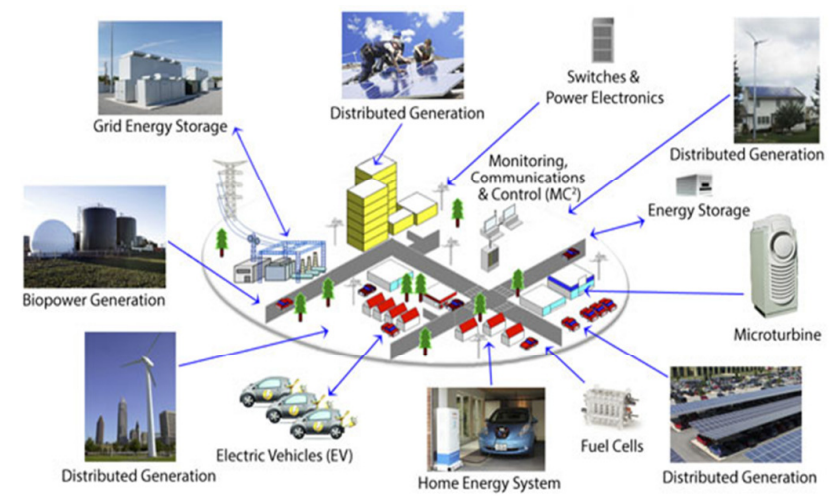

Gambar 1. Microgrid System [2]

Microgrid dapat dikombinasikan dengan beberapa sumber energy yang tersedia dan dapat dilakukan pada proses pembangkitan berskala kecil, biasanya di bawah $10 \mathrm{MW}$. Pembangkitan listrik dengan kapasitas tinggi akan memberikan keuntungan ekonomi yang lebih tinggi, tetapi pada umumnya terdapat beberapa masalah pada proses pendistribusian untuk wilayah yang terpisah satu sama lain. Penerapan sistem microgrid di Indonesia sangat cocok karena kondisi geografis yang terdiri lebih dari 15.000 pulau yang tersebar sepanjang garis khatulistiwa. Dengan ratio elektrifikasi hanya $87 \%$ dan melimpahnya sumber energy terbarukan, diharapkan teknologi sistem microgrid ini menjadi teknologi terbaik dan cerdas untuk diterapkan di Indonesia [3] Pada sistem microgrid ini, memungkinkan penggunakan sumber energi bersih dan lebih efisien untuk sistem pendistribusiannya, seperti angin, surya serta dapat meningkatkan kesehatan lingkungan dan ekonomi masyarakat [2].

\section{METODE PENELITIAN}

Penelitian dilaksanankan di Fakultas Teknik Universitas Udayanan Bukit Jimbaran yang dimulai pada bulan Juli 2016 sampai bulan September 2016.

Data yang digunakan pada penelitian ini adalah data beban setiap gedung di FT Universitas Udayana, single line diagram FT Universitas Udayana, serta data smart microgrid system (PLTS, Wind Turbine, dan genset). Desain jaringan dengan model suplly yang bersumber dari PLN, smart microgrid system, dan generator set yang akan disimulasikan menggunakan Load Flow Analysis dan Reliability Accessment.

\section{HASIL DAN PEMBAHASAN}

\section{A. Skema Smart Microgrid System}

Smart microgrid system di Fakultas Teknik Universitas Udayana akan dipasang gedung DH Jurusan Teknik Elektro (JTEK). Smart microgrid system ini akan menyuplai beban yang ada di gedung DH JTEK yang digunakan sebagai gedung perkuliahan. Smart microgrid system terdiri dari PLTS dengan kapasitas $24 \mathrm{kWp}$, Wind Turbin $5 \mathrm{kWp}$ yang menggunakan sistem baterai $240 \mathrm{kVAh}$ sebagai media penyimpan muatan listrik dan generator set $20 \mathrm{kVA}$ sebagai sistem back up apabila jaringan utility mengalami ganggunan. Tidak hanya gedung DH yang akan disupai dari smart microgrid system, akan tetapi gedung DI dan DJ akan mendapat suplai dari sistem untuk sistem penerangan selama hari libur. Skema smart microgrid dapat dilihat pada gambar 2.

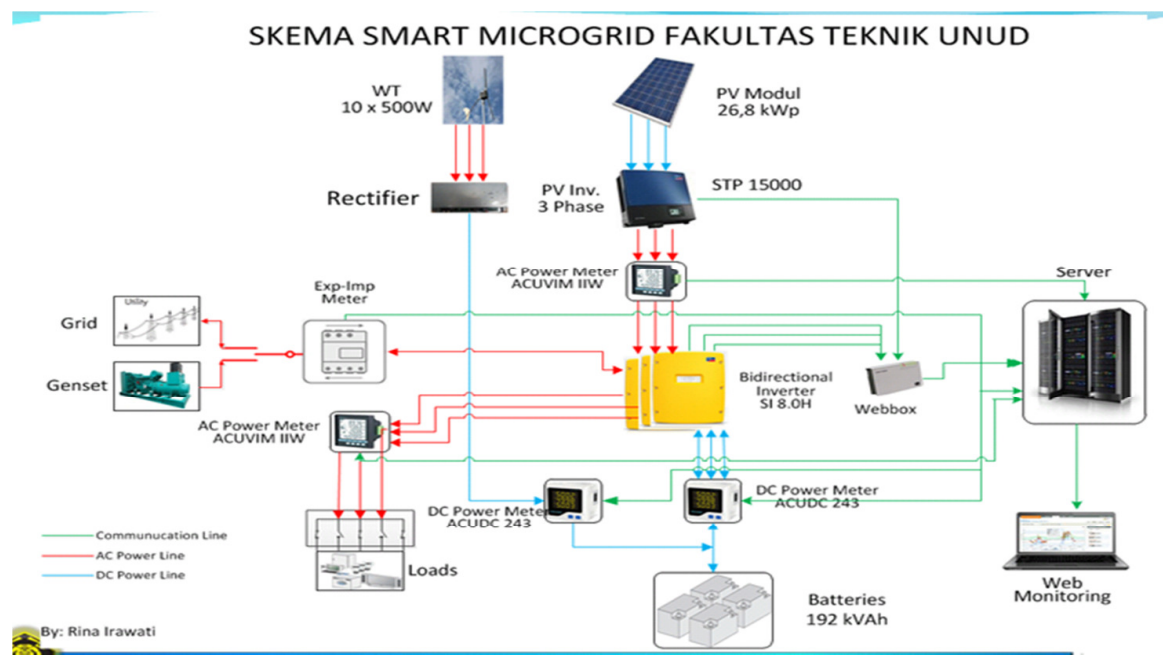

Gambar 2. Skema Smart Microgrid FT Unud [3] [6]

Berdasarkan skema smart microgrid system, akan didesain jaringan listrik secara keseluruhan di Fakultas Teknik Universitas Udayana Bukit Jimbaran yang selanjutnya akan dianalisis rugi-rugi daya (losses) yang dihasilkan dan tingkat keandalan pada kondisi ketika jaringan belum terinterkoneksi

Margareta Yuniari: Analisis Model Supply Pada... dengan smart microgrid system dan kondisi ketika jaringan sudah terinterkoneksi dengan smart microgrid system.

\section{A. Data Hasil Pengukuran Beban}

Pengukuran beban di gedung-gedung Arsitektur, Teknik Mesin, Teknologi Infomasi, Dekanat, dan Undagi dilakukan 
sesaat pada jam-jam tertentu. Tujuannya dilakukan pengukuran sesaat adalah untuk mengetahui seberapa besar kebutuhan beban di setiap gedung-gedung tersebut. Gedunggedung ini nantinya juga akan mendapat suplai dari smart microgrid system yang terdiri dari PLTS $26.4 \mathrm{kWp}$, Wind Turbin $5 \mathrm{kWp}$ dengan sistem baterai $240 \mathrm{kVAh}$ serta sistem backup berupa Genset $20 \mathrm{kVA}$. Data beban setiap gedung di FT Unud dapat dilihat pada tabel 1.

TABEL I

DATA BEBAN SETIAP GEDUNG DI FT UNUD

\begin{tabular}{|c|c|c|c|}
\hline No & \multicolumn{2}{|c|}{ Nama Gedung } & Total Daya Aktif (kW) \\
\hline 1 & $\mathrm{DH}$ & \multirow{3}{*}{ JTEK } & 57,84 \\
\hline 2 & DI & & 14,25 \\
\hline 3 & DJ & & 4,58 \\
\hline 4 & TI & TI & 28,89 \\
\hline 5 & DEKANAT & DEKANAT & 24,61 \\
\hline 6 & UNDAGI & UNDAGI & 1,09 \\
\hline 7 & $\overline{\mathrm{DG}}$ & \multirow{4}{*}{ Teknik Mesin } & 7,44 \\
\hline 8 & $\mathrm{DC}$ & & 7,63 \\
\hline 9 & $\overline{\mathrm{DD}}$ & & 5,21 \\
\hline 10 & $\overline{\mathrm{DE}}$ & & 3,88 \\
\hline 11 & $\mathrm{DF}$ & \multirow{3}{*}{ Arsitektur } & 7,29 \\
\hline 12 & DB & & 10,77 \\
\hline 13 & DK & & 0,001 \\
\hline \multicolumn{3}{|c|}{ Total } & 173,54 \\
\hline
\end{tabular}

*Jurusan Teknik sipil tidak termasuk, karena letaknya yang terpisah dari keempat jurusan lainnya (tidak disuplai oleh jenis trafo KA-0298)

Berdasarkan tabel 1 diketahui bahwa total beban tertinggi terdapat di gedung DH JTEK yakni sebesar 57,845 kW dan total beban terendah terdapat di Gedung DK, yakni sebesar $0,001 \mathrm{~kW}$. Gedung DK adalah salah satu gedung di Jurusan Arsitektur yang saat ini tidak digunakan lagi, dengan kata lain sebagai tempat penyimpanan barang-barang yang sudah tidak digunakan. Gedung DH adalah gedung yang akan menjadi tempat dipasangnya PLTS dan Wind Turbin dengan sistem baterai. Selain itu, gedung DI dan DJ akan disuplai juga oleh PLTS dan Wind Turbin pada saat hari libur

\section{B. Analisis Kondisi Sistem Kelistrikan di FT Udayana Bukit Jimbaran Sebelum Masuknya Smart Microgrid System}

Pada analisis kondisi sistem kelistrikan di Fakultas Teknik Universitas Udayana Bukit Jimbaran sebelum masuknya smart microgrid system, berdasarkan desain yang dibuat di ETAP 12.6.0. Kondisi ini merupakan kondisi existing dimana jaringan hanya mendapat suplai dari PLN.

Berdasarkan hasil analisis, dapat diketahui bahwa jaringan hanya mendapat suplai dari PLN melalui trafo KA0298 dengan kapasitas 200 kVA. Total gedung yang disuplai sebanyak 13 gedung yang tersebar di Fakultas Teknik dengan total beban adalah sebesar 173,54 kW. Besarnya losses yang dihasilkan adalah sebesar $6,4 \mathrm{~kW}$ dan persentase losses dari total beban adalah sebesar $3,68 \%$.

Untuk nilai dari masing-masing indeks keandalan, yakni SAIFI: 0,7869 kali/pelanggan.tahun atau 3 kali terjainya gangguan dalam waktu 4 tahun, SAIDI: 3,6190 jam/pelangan.tahun atau dalam waktu 1 tahun terjadinya pemadaman selama 3 jam 40 menit untuk setiap pelanggan, dan CAIDI: 4,599 jam/gangguan pada pelanggan atau durasi gangguan untuk setiap pelanggan selama 4 jam 30 menit setiap pelanggan.

Berdasarkan titik letak beban, tingkat keandalan tertinggi terdpat di gedung DJ JTEK yakni $0,7830 \mathrm{kali} / \mathrm{tahun}$ atau 3 kali terjadinya gangguan dalam waktu 4 tahun dengan durasi pemadaman 4,47 jam, dan durasi terjadinya gangguan setiap tahun 3,4980 jam/tahun atau 3 jam 29 menit durasi terjadinya gangguan setiap tahun. Untuk model desain jaringan dapat dilihat pada gambar 3 .

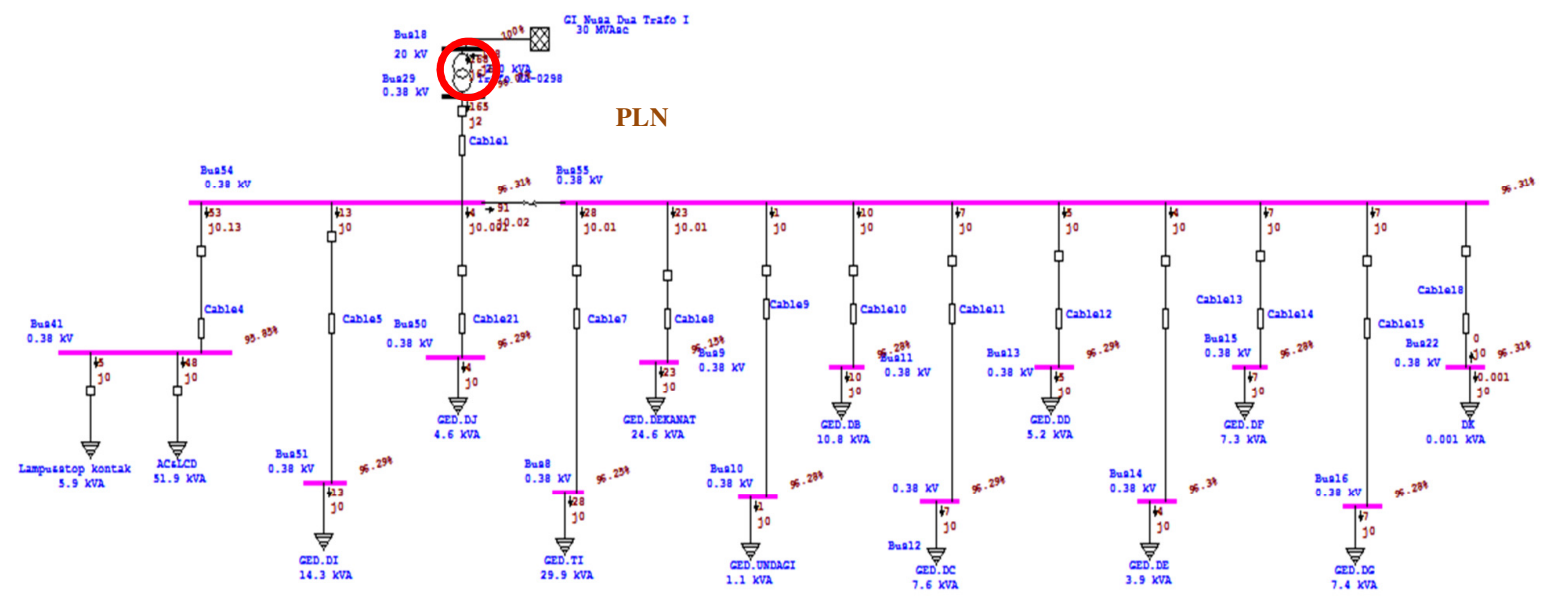

Gambar 3. Desain jaringan ketika disuplai oleh PLN 


\section{Analisis Kondisi Sistem Kelistrikan di FT Udayana Setelah Masuknya Smart Microgrid System (Kondisi I)}

Masuknya smart microgrid system jaringan listrik tentunya memiliki desain yang berbeda. Smart microgrid system merupakan suatu kesatuan sistem yang terdiri dari PLTS 24 $\mathrm{kWp}$,Wind Turbin $5 \mathrm{kWp}$ yang menggunakan sistem baterai dengan kapasitas penyimpanan $240 \mathrm{kVAh}$, dan generator set.
Besarnya kapasitas smart microgrid system dilihat dari besarnya kapasitas baterai sebagai sistem penyimpanan untuk PLTS dan Wind Turbin. Dengan kapasitas baterai adalah kapasitas baterai $240 \mathrm{kVAh}$ dan bekerja selama 8 jam, kapasitas generator set $20 \mathrm{kVA}$, maka kapasitas total dari smart microgrid system adalah sebesar $50 \mathrm{kVA}$. Untuk model desain jaringan dapat dilihat pada gambar 4.

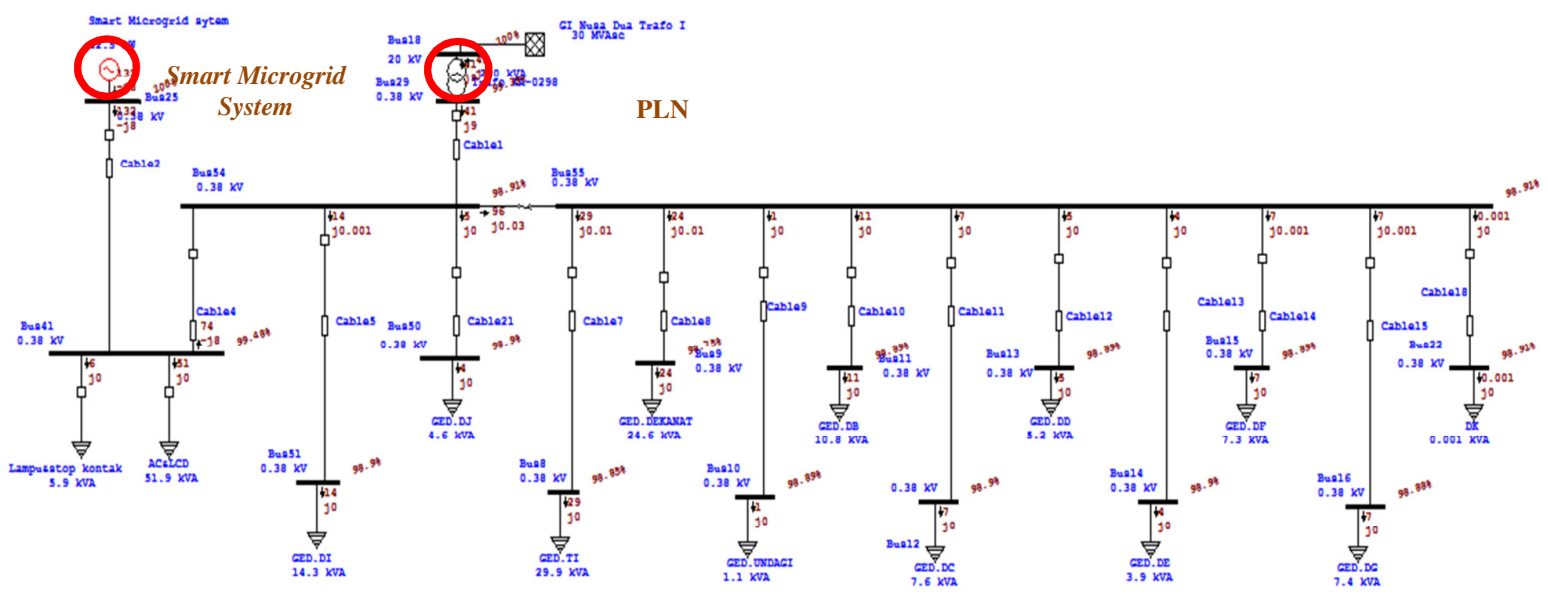

Gambar 4. Desain jaringan ketika disuplai oleh PLN dan Smart Microgrid System

Berdasarkan gambar 4, dapat diketahui bahwa jaringan mendapat suplai dari dua sumber, yakni PLN dan smart microgrid system. Total gedung yang disuplai adalah sebanyak 13 gedung dengan total beban keseluruhan adalah sebesar 173,54 kW. Besarnya losses yang dihasilkan adalah sebesar 1,6 kW dan persentase losses dari total beban adalah sebesar $0,92 \% \%$.

Untuk nilai dari masing-masing indeks keandalan, yakni SAIFI: 0,1029 kali/pelanggan.tahun atau 1 kali terjainya gangguan dalam waktu 10 tahun, SAIDI: 1,9229 jam/pelangan.tahun atau dalam waktu 1 jam 55 menit tahun terjadinya pemadaman, dan CAIDI 18,686 jam/gangguan pada pelanggan.

Berdasarkan titik letak beban, tingkat keandalan tertinggi terdapat di gedung DH (untuk beban AC dan lampu) JTEK, yakni 0,0488 rata-rata gangguan/tahun dan durasi terjadinya gangguan setiap tahun adalah $1,8200 \mathrm{jam} / \mathrm{tahun}$.
D. Analisis Kondisi Sistem Kelistrikan di FT Udayana Setelah Masuknya Smart Microgrid System dan Genset (Kondisi II)

Pada analisis ini, diketahui bahwa jaringan mendapat suplai dari 3 sumber, yakni PLN, smart microgrid system, dan genset. Total gedung yang disuplai sebanyak 13 gedung yang tersebar di Fakultas Teknik dengan total beban adalah sebesar 175,54 $\mathrm{kW}$. Besarnya losses yang dihasilkan adalah $1,2 \mathrm{~kW}$ dan persentase dari total beban adalah sebsar $0,69 \mathrm{~kW}$.

Untuk nilai masing-masing indeks keandalan, yakni SAIFI: 0,1045 kali/pelanggan.tahun atau 1 kali terjadinya gangguan dalam kurun waktu 10 tahun, SAIDI: 1,9536 jam/pelanggan.tahun atau dalam setahun durasi pemadaman terjadi selama 1 jam 11 menit, dan CAIDI: 18,592 jam/gangguan.

Berdasarkan titik letak leban, tingkat keandalan tertinggi terdapat di gedung DH JTEK, yakni 0,045 rata-rata gangguan/tahun dan durasi terjadinya gangguan setiap tahun adalah 2,0350 jam/tahun. Untuk model desain jaringan dapat dilihat pada gambar 5 .

Margareta Yuniari: Analisis Model Supply Pada... 


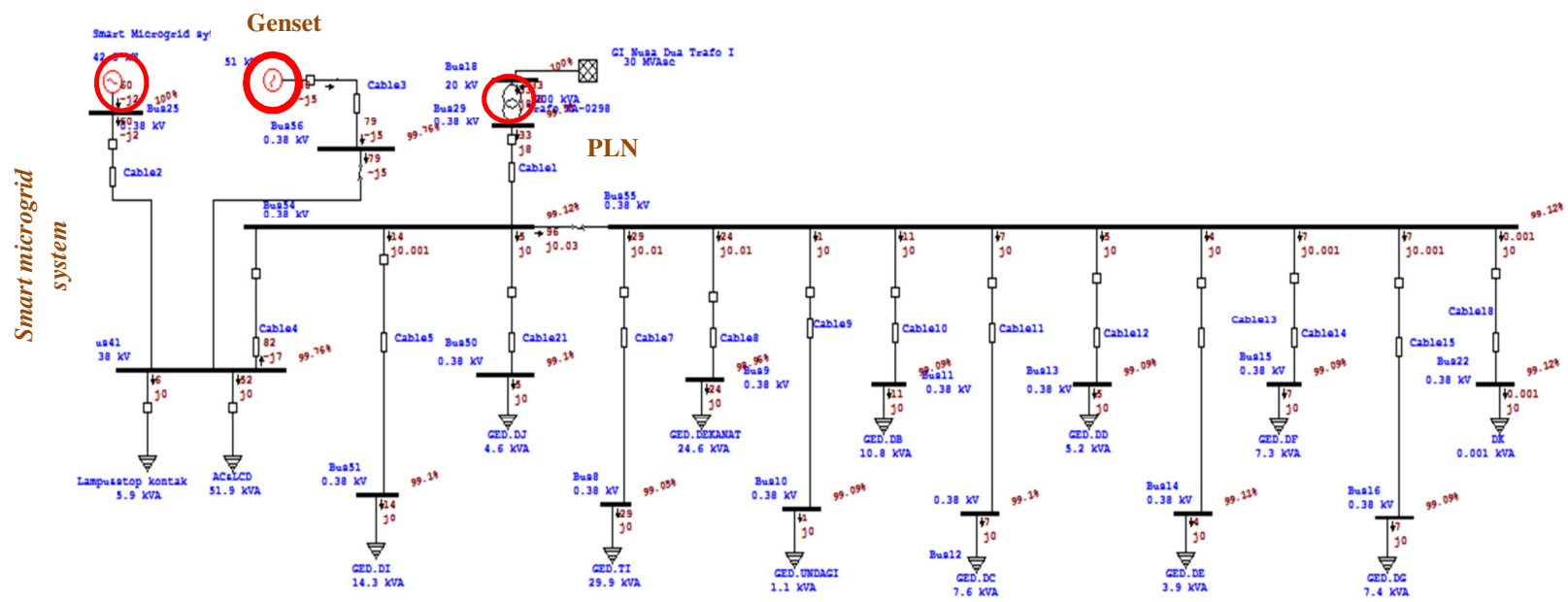

Gambar 5. Desain jaringan ketika disuplai dari PLN, smart microgrid system, dan genset

\section{Kesimpulan}

Berdasarkan desain jaringan maka diperoleh rugi-rugi daya (losses) pada jaringan listrik Fakultas Teknik Universitas Udayana Bukit Jimbaran sebelum masuknya smart microgrid system dan sesudah masuknya smart microgrid system. Sebelum masuknya smart microgrid system ke jaringan, diperoleh losses sebesar $6,4 \mathrm{~kW}$ atau $3,68 \%$ dari total beban ketika jaringan disuplai dari PLN. Setelah masuknya smart microgrid system dan generator set ke jaringan PLN, diperoleh losses sebesar 1,2 $\mathrm{kW}$ atau mengalami penurunan losses sebesar $0,69 \%$ dari total beban sebesar 173,54 kW.

Untuk menghitung indeks keandalan titik beban dan indeks keandalan titik beban dan indeks keandalan sistem yang biasanya digunakan meliputi angka keluar (outage number) dan lama perbaikan (repair duration) dari masingmasing komponen [7] [8].

Indeks keandalan yang diperoleh pada jaringan Fakultas Teknik Universitas Udayana Bukit Jimbaran sebelum masuknya smart microgrdi system adalah SAIFI: 0,7869 kali/pelanggan.tahun atau 3 kali terjadinya gangguan dalam waktu 4 tahun, SAIDI: 3,6190 jam/pelanggan.tahun atau dalam waktu 1 tahun terjadinya pemadaman selama 3 jam 40 menit untuk setiap pelanggan, dan CAIDI: 4,599 jam/gangguan pada pelanggan atau durasi gangguan untuk setiap pelanggan selama 4 jam 30 menit. Indeks keanda;an setelah masuknya smart microgrid system ketika terinterkoneksi dengan PLN, yakni SAIFI: 0,1029 kali/pelanggan.tahun atau terjadinya 1 kali gangguan dalam waktu 10 tahun, SAIDI: 1,9229 jam/pelanggan atau terjadinya gangguan 1 jam 50 menit detiap tahun, dan CAIDI:18,686 jam/gangguan pada pelanggan. Ini adalah indeks keandalan terbaik yang diperoleh dan dipengaruhi oleh beberapa faktor diantaranya adalah keberhasilan bagian dari sistem itu sendiri Semakin banyak komponen yang terdapat dalam sistem sakan berpengaruh pada tingkat keandalan sustu jaringan [5].

Berdasarkan titik letak beban, tingkat keandalan tertinggi terdapat di gedung DH. Hal ini karena letak gedung DH paling dekat dengan sumber supply tenaga listrik sehingga ini akan berpengaruh pada tingkat keandalan suatu jaringan, dimana semakin dekat letak tempat atau lokasi beban dari sumber suplai tenaga listrik maka nilai tingkat keandalannya akan semakin tinggi begitupun sebaliknya jika lokasi beban dari sumber semakin jauh jari sumber suplai tenaga listrik maka nilai tingkat keandalannya akan semakin rendah [5].

\section{REFERENSI}

[1] The U.S. Department of Energy's Microgrid Initiative,DOE Microgrid Workshop Report,August.30-31,2011,[online]. Available:https://energy.gov/sites/prod/files/Microgrid\%20Workshop $\% 20$ Report $\% 20$ August $\% 202011$.pdf

[2] Nyserda.Available:https://www.nyserda.ny.gov/AllPrograms/Programs/NY-Prize/Resources-for-applicants/Microgrids101. [online]

[3] IAD Giriantari, Rina Irawati. Smart Microgrid System with Supply from Hybrid. ICGTEIS2016. Bali, Indonesia:Udayana University, 2016

[4] Darma Putra, Krisna. 2015, Perencanaan Sistem Jaringan Mikro (Microgrid) dengan Supply dari Pembangkit Listrik Tenaga Surya (PLTS) dan Generator Set di Jurusan Teknik Elektri Universitas Udayana. Teknologi Elektro, Vol.14. No. 2 (Juli - Desember): 69-74

[5] Bilinton, A dan Ronald. Reliability Evaluation of Power System. $2^{\text {nd }}$ Ed. New York:PlenumPress, 1996.

[6] Rina Irawati, Pengembangan Smart Microgrid Untuk Integrasi Pembangkit berbasis Energi Terbarukan,Jakarta: Kementrian Energi dan Sumber Daya Mineral, Focus Group Disscussion CORE Universitas Udayana,Oktober, 2016.

[7] Hartati, Rukmi S, Sukerayasa I Wyn.,Setiawan I Nym., Ariastina Wyn Gd. 2007. Penentuan Angka Keluaran Untuk Evaluasi keandalan Sistem Distribusi Tenaga listrik. Teknologi Elektro, Vol.6, No.2 (JuliDesember).

[8] SPLN (Standar Perusahaan Listrik Negara) 59:1985. Keandalan Pada Sistem Distribusi $20 \mathrm{kV}$ dan $6 \mathrm{kV} .1985$.

[9] Iswadiah, Sudibyo, Setiawan, E.A., 2010. Analisis Kinerja Pembangkit Listrik Energi terbarukan Pada Model Jaringan Listrik Mikro Arus Searah. Politeknologi, Vol 9. No.2. 